\title{
Studi Awal Pemanfaatan Turbin Screw pada Aliran Sungai Kecil di Kota Jambi
}

\author{
Fadli Eka Yandra ${ }^{1}$, S. Umar Djufri ${ }^{2}$ \\ ${ }^{1,2}$ Teknik Listrik, Fakultas Teknik, Universitas Batanghari \\ Correspondence Email: fadli.eka.yandra@unbari.ac.id
}

\begin{abstract}
Abstrak. Penggunaan archimedes screw telah bergeser pemanfaatannya dari pompa menjadi sumber energi tenaga air pada head rendah sebagai turbin air. Kinerja turbin archimedes srew dipengaruhi oleh beberapa parameter antara lain tingkat rendaman turbin, sudut kemiringan turbin, pitch ratio, dan jumlah sudu. Kota Jambi yang berkontur dataran rendah yang dilewati daerah aliran sungai Batanghari membuat potensi drainasenya bisa dimanfaatkan untuk menjadi pembangkit listrik tenaga air berskala kecil dengan menggunakan turbin screw, karena kontur Kota Jambi yang rendah, berakibat tekanan air kecil walaupun debitnya kadang besar akibat luapan sungai Batanghari, maka pilihan turbin dengan Head rendah menjadi solusinya, pada penelitian ini, dilakukan studi perhitungan potensi aliran drainase yang terdapat di Kota Jambi, apakah bisa dimanfaatkan atau tidak.
\end{abstract}

Kata kunci: archimedes screw; rendaman turbin; kemiringan turbin; pitch ratio; jumlah sudu; debit air.

Abstract. The use of archimedes screw has shifted its use from pumps to a source of hydropower at low heads as water turbines. Archimedes srew turbine performance is influenced by several parameters including turbine submersion level, turbine tilt angle, pitch ratio, and number of blades. The contour of the lowland Jambi city that is passed by the Batanghari watershed makes the drainage potential can be utilized to become a small-scale hydroelectric power plant using screw turbines, because the contour of Jambi City is low, resulting in small water pressure although the discharge is sometimes large due to the overflow of the Batanghari river, then the choice of turbine with a low head is the solution, in this study, a study was made to calculate the potential drainage flow in the city of Jambi, whether it can be used or not.

Keyword: archimedes screw; turbine immersion; turbine tilt; pitch ratio; number of blades; air discharge.

\section{PENDAHULUAN}

Banyaknya aliran sungai kecil yang berada di Kota Jambi, membuat penulis tertarik untuk memanfaatkan sumber Energi Terbarukan tersebut sebagai sumber energi penerangan di daerah aliran sungai, agar aliran sungai bisa menjadi tempat yang menarik dan bersih. Untuk memanfaatkan sumber energinya, maka perlu dilakukan perhitungan debit air dan potensi energi yang bisa dimanfaatkan pada aliran sungai tersebut, untuk itu perlu dilakukan kajian dan pengujian pada sungai-sungai yang berada disekitar Kota Jambi. Untuk memanfaatkan sumber energinya, maka perlu dilakukan perhitungan debit air dan potensi energi yang bisa dimanfaatkan pada aliran sungai tersebut, untuk itu perlu dilakukan kajian dan pengujian pada sungai-sungai yang berada disekitar Kota Jambi.

Pembangkit listrik tenaga air atau PLTA bekerja berdasarkan perbedaan ketinggian (head) dan debit air setiap detiknya [1]. Gambar 1 menunjukkan prinsip kerja pembangkit listrik turbin archimedes screw, dimana aliran air melewati kisi-kisi turbin sehingga menggerakkan poros turbin (energi mekanik) dan menghasilkan energi listrik melalui generator [2].

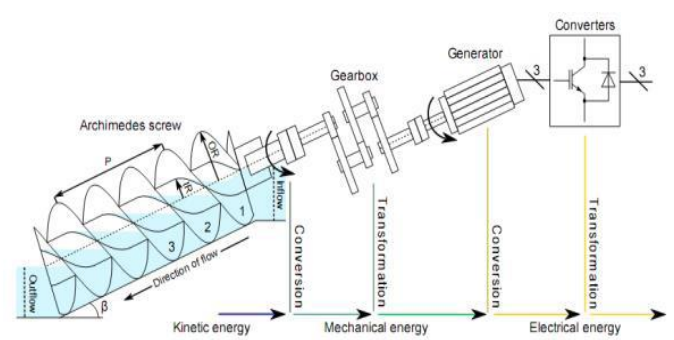

Gambar 1. Skema Pembangkit Listrik Turbin Archimedes Srew [2]

Air merupakan salah satu sumber energi, karena pada air tersimpan energi potensial untuk kondisi air jatuh dan energi kinetik untuk kondisi air yang mengalir. Sesuai dengan kaidah kekekalan energi yang menyatakan bahwa suatu bentuk energi tidak dapat dimusnahkan tetapi dapat diubah bentuk menjadi energi lain. Penjelasan kaidah kekekalan energi tadi dapat diilustrasikan pada air jatuh pada ketinggian tertentu yang didalamnya terkandung energi potensial yang merupakan proses alamiah apabila dimanfaatkan untuk memutar turbin air maka dapat diubah menjadi energy mekanik dan elektrik tentunya dengan menempatkan sebuah generator. Tenaga air merupakan sumber energi yang bersifat non-depletable (tidak dapat habis) namun begitu sumber air bias saja mengalami kekurangan intensitas hal ini dipengaruhi oleh iklim yang menyangkut angka curah hujan serta kerusakan alam 
seperti penggundulan hutan dan pengrusakan struktur tanah.

\section{Hidrograph}

Debit air tidak dapat diharapkan konstan, selalu berubah setiap waktu. Perubahan ini disebabkan karena perubahan musim, perubhan bentuk penampang saluran/sungai akibat pengikisan atau erosi, penggunaak air yang bervariasi (untuk pengairan, industry perikanan, dan keperluan lain) serta sebab lain yang sulit diramalkan seperti sifat-sifat geografis setempat.

Oleh karena itu perlu didata keadaan sumber daya perwaktu yang ditentukan, dalam setiap kurva hydrograph yang menunjukkan hubungan antara debit dengan waktu. Siklus waktu bias saja pendek (siklus harian, mingguan) maupun panjang (bulanan, tahunan).

Untuk memperoleh data yang lebih lengkap, debit suatu sungai dapat diramalkan dari besarnya curah hujan. Data curah hujan selama puluhan tahun pada daerah tangkapan hujan dapat diperoleh dari Badan Meteorolgi dan Geofisika (BMG). Hubungan antara besarnya curah hujan dengan debit aliran sungai (run of river) yang dihasilkan dapat diperkirakan berdasarkan kerugian yang terjadi. Kerugian-kerugian tersebut meliputi penguapan (evaporasi), perembesan (seepage) kedalam tanah, penggunaan air sungai pada daerah hulu, dan besarnya kerugian tersebut tergantung dar kondisi geologi atau setidaknya dapat diperkirakan., keadaan iklim, tingkat penghunian penduduk, yang semuanya dapat dicari datanya.

\section{Daya Hidrolis}

Dua komponen obyektif dalam analisis pembangkit tenaga air adalah head dan laju aliaran/debit. Head adalah beda ketinggian antara reservoir, head dalam tenaga air diartikan juga sebagai tinggi air jatuh.

Di ilustrasikan bila sejumlah air seberat $1 \mathrm{~kg}$ jatuh dari ketinggian $\mathrm{H}$ meter ke tempat yang lebih rendah pada kecepatan nol, maka kerja yang dilakukan oleh air tersebut adalah $1 \mathrm{~kg} .1 H$ meter $=1 H \mathrm{~kg} . \mathrm{m}$. Ketika selama setiap detik jumlah air $Q$ berjalan sepanjang perbedaan ketinggian $H$ ke arah grafitasi, maka air tersebut melakukan kerja tiap detik, atau membawa keluaran (work per second), Ph dalam joule/s atau watt.

$P h=\rho . Q \cdot g . H$.

Dimana :

$P h=$ power/kerja (Watt)

$\rho=$ berat jenis air $\left(998,3 \mathrm{~kg} / \mathrm{m} 3\right.$ pada suhu $\left.20^{\circ} \mathrm{C}\right)$

$Q=$ jumlah air yang lewat tiap detik atau Flowrate $(\mathrm{m} 3 / \mathrm{s})$

$\mathrm{g}=$ percepatan gravitasi bumi $(9,81 \mathrm{~m} / \mathrm{s} 2)$

$\mathrm{H}=$ perbedaan ketinggian bersih (Net-head) dalam (m)

$P h$ merupakan keluaran teoritis tanpa kerugian ketika air jatuh air jatuh, namun dalam kenyataannya motor hidrolis tidak dapat mengkonversi semua energi hidrolis ke energi mekanis tanpa adanya kerugiankerugian (losses) sehingga keluaran efektif).

\section{Debit}

Debit aliran sungai menurut Bambang Triatmodjo adalah jumlah air yang mengalir melalui tampang lintang sungai tiap satu satuan waktu, yang biasanya dinyatakan dalam meter kubik per detik (m3/dt). Debit sungai, dengan distribusinya dalam ruang dan waktu, merupakan informasi penting yang diperlukan dalam perencanaan bangunan air dan pemanfaatan sumberdaya air.

\section{Klasifikasi kecepatan air}

Karakteristik kecepatan air di sungai tidak jauh berbeda dengan karakteristik kecepatan air di suatu saluran. Karena aliran di sungai pada umumnya adalah turbulen seperti halnya aliran di saluran, maka debit aliran melalui saluran terbuka dapat dihitung dengan rumus berikut:

$\mathrm{Q}=\mathrm{A} \mathrm{V}\left(\mathrm{m}^{3} / \mathrm{s}\right) \ldots \ldots \ldots \ldots \ldots \ldots \ldots \ldots \ldots(2)$

Kecepatan aliran melalui saluran terbuka dapat dihitung dengan beberapa rumus berikut: Koefisien Chesy dapat dinyatakan dengan koefisien Manning dengan persamaan $C=1 n R 16$, dimana $\mathrm{n}$ adalah nilai koefisien Manning yang merupakan fungsi dari bahan dinding saluran.

\section{METODE}

Metoda penelitian yang penulis lakukan berupa pengumpulan data cuaca, daerah aliran sungai Kota Jambi, debit air dan perhitungan ketinggian head. Mikrohidro adalah istilah yang digunakan untuk instalasi pembangkit listrik yang mengunakan energi air. Kondisi air yang bisa dimanfaatkan sebagai sumber daya (resources) penghasil listrik adalah memiliki kapasitas aliran dan ketinggian tertentu dari instalasi. Semakin besar kapasitas aliran maupun ketinggiannya dari instalasi maka semakin besar energi yang bias dimanfaatkan untuk menghasilkan energi listrik.

Biasanya Mikrohidro dibangun berdasarkan kenyataan bahwa adanya air yang mengalir di suatu daerah dengan kapasitas dan ketinggian yang memadai. Istilah kapasitas mengacu kepada jumlah volume aliran air persatuan waktu (flow capacity) sedangan beda ketingglan daerah aliran sampai ke instalasi dikenal dengan istilah head. Mikrohidro juga dikenal sebagai white resources dengan terjemahan bebas bisa dikatakan "energi putih". Dikatakan demikian karena instalasi pembangkit listrik seperti ini mengunakan sumber daya yang telah disediakan oleh alam dan ramah lingkungan. Suatu kenyataan bahwa alam memiliki air terjun atau jenis lainnya yang menjadi tempat air mengalir. Dengan teknologi sekarang maka energi aliran air beserta energi perbedaan ketinggiannya dengan daerah tertentu (tempat 
instalasi akan dibangun) dapat diubah menjadi energi listrik.

\section{HASIL DAN PEMBAHASAN}

\section{Daerah aliran sungai Kota Jambi}

Peta berikut memperlihatkan daerah aliran sungai yang terdapat di Kota Jambi

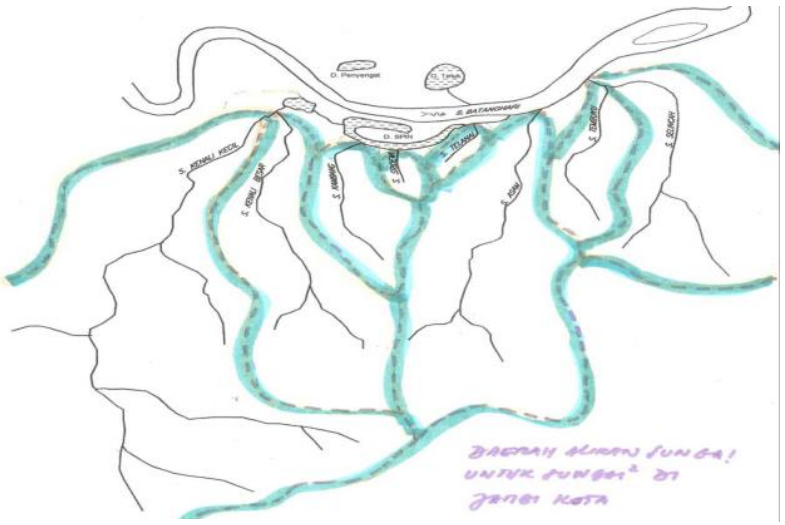

Gambar 2. Daerah aliran sungai Kota Jambi

Tabel 1. Lokasi Genangan Akibat luapan sungai Batanghari

\begin{tabular}{clcccc}
\hline No. & \multicolumn{1}{c}{ Lokasi / Kecamatan } & \multicolumn{2}{c}{ Besaran } & \multicolumn{2}{c}{ Waktu } \\
& & Luas (Ha) & Tinggi (m) & Waktu (hari) & Frekuensi (kali/thn) \\
\hline A & Banjir karena luapan sungai Batanghari & & & & \\
1 & Kec. Pasar Jambi & 120 & $0,5-2$ & $4-20$ & 2 \\
2 & Kec. Jelutung & 157 & $1-2$ & $4-20$ & 2 \\
3 & Kec. Telanaipura & 900 & $1-2$ & $4-20$ & 2 \\
4 & Kec. Jambi Timur - Sungai Tembuku & 140 & $1-3$ & $4-20$ & 2 \\
5 & Kec. Jambi Timur, sungai selincah & 750 & $1-4$ & $5-30$ & 2 \\
6 & Kec. Danau Teluk & 1450 & $1-3$ & $5-25$ & 2 \\
7 & Kec. Pelayangan & 98 & $1-3$ & $5-25$ & 2 \\
\hline
\end{tabular}

Tabel 2. Lokasi Genangan Akibat curah hujan

\begin{tabular}{|c|c|c|c|c|c|}
\hline \multirow[t]{2}{*}{ No. } & \multirow{2}{*}{ Lokasi / Kecamatan } & \multicolumn{2}{|c|}{ Besaran } & \multicolumn{2}{|c|}{ Waktu } \\
\hline & & Luas $(\mathrm{Ha})$ & Tinggi $(\mathrm{m})$ & Waktu (hari) & Frekuensi (kali/thn) \\
\hline $\mathrm{B}$ & Banjir karena genangan rutin & & & & \\
\hline 8 & Jl. Rd Pamuk (Pertamina) & 4.00 & $0.5-1.5$ & 10 & 6 \\
\hline 9 & Talang banjar & 3.00 & $0.4-0.6$ & 3 & 6 \\
\hline 10 & Budiman & 3.28 & $0.4-0.6$ & 3 & 6 \\
\hline 11 & Terminal Pasar & 1.54 & $0.2-0.4$ & 5 & 10 \\
\hline 12 & Pasar Jambi & 1.24 & $0.2-0.4$ & 5 & 10 \\
\hline 13 & Jl. Abdul Rahman Saleh & 1.50 & $0.2-1.0$ & 3 & 5 \\
\hline 14 & Simpang III Sipin & 4.50 & $0.2-0.8$ & 3 & 4 \\
\hline 15 & Kel. Rawasari & 2.00 & $0.4-0.6$ & 3 & 4 \\
\hline 16 & Jalan Siswa & 1.50 & $0.4-0.6$ & 5 & 5 \\
\hline 17 & Jalan Metu & 1.60 & $0.3-0.5$ & 6 & 9 \\
\hline 18 & Hotel Aini & 3.25 & $0.5-0.7$ & 6 & 9 \\
\hline 19 & Jl. Cokroaminoto, Serunai Malam & 2.08 & $0.6-1.0$ & 4 & 7 \\
\hline 20 & Jl. Sri Sudewi & 1.00 & $1.0-1.5$ & 8 & 17 \\
\hline 21 & Jl. Sungai Putri & 1.42 & $0.3-0.6$ & 5 & 10 \\
\hline
\end{tabular}

Lokasi genangan dapat dilihat pada peta berikut:
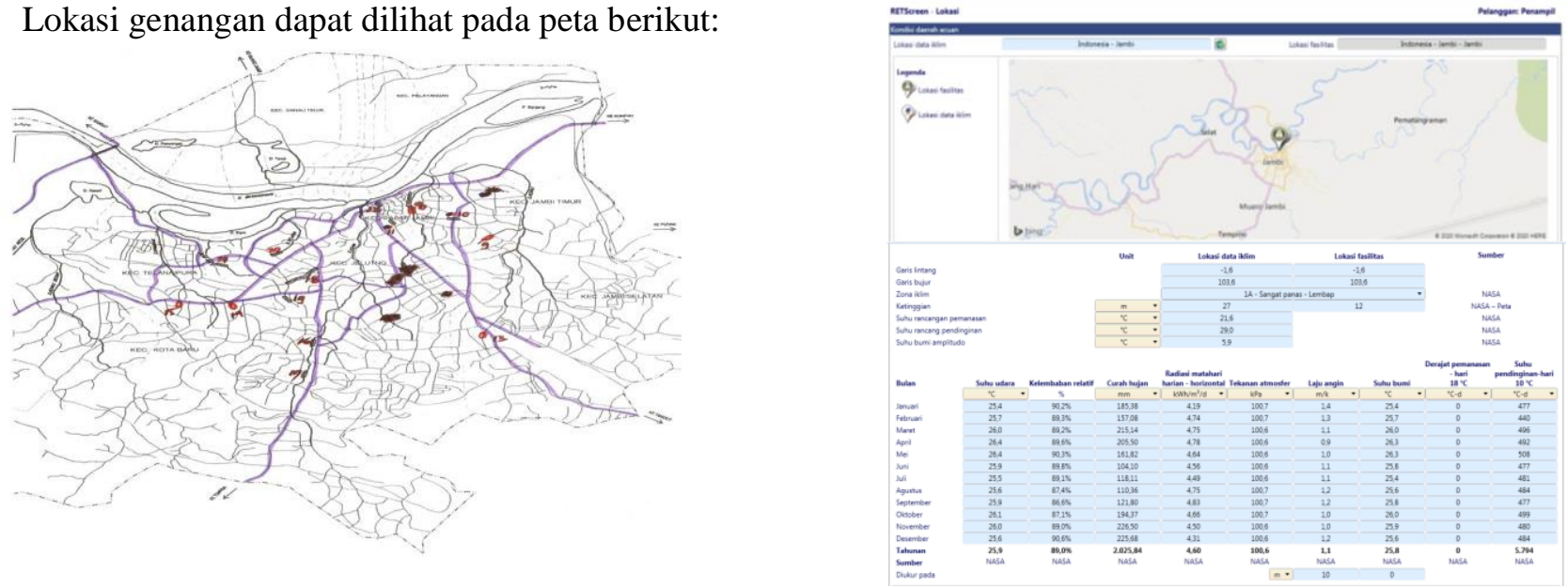

Perhitungan cuaca 


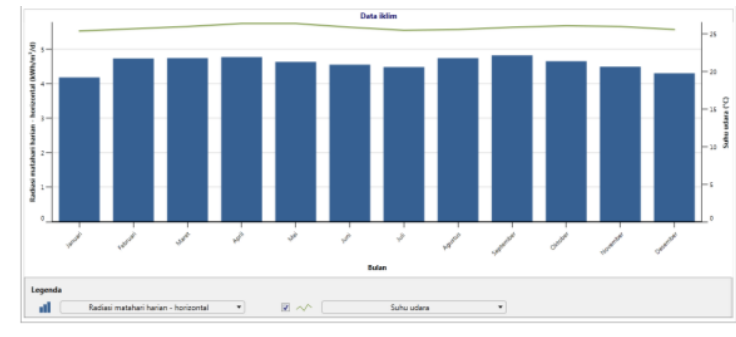

Dari tabel cuaca diatas terlihat bahwa rata-rata $100 \mathrm{~mm}$ perbulannya, sehingga drainase atau sungaisungai kecil yang ada di Kota Jambi, berpotensi untuk dimanfaatkan aliran airnya.

\section{SIMPULAN}

Drainase yang ada di Kota Jambi cukup memenuhi sarat untuk dimanfaatkan sebagai sumber energi listrik dengan menggunakan turbin screw karena debit yang kecil dan head yang rendah.

\section{DAFTAR PUSTAKA}

[1] A. Nurdin, "Optimalisasi Transmisi PLTA - Pico Hydro sebagai Penunjang Konversi EnergiMekanik Menjadi Listrik," Universitas Sebelas Maret, Surakarta, 2016.

[2] J. Rohmer, D. Knittel, G. Sturtzer, D. Flieller, and J. Renaud, "Modeling and experimental results ofan Archimedes screw turbine," Renewable Energy, vol. 94, pp. 136-146, 2016.

[3] M. Stefanizzi and B. Fortunato, "Experimental investigation and performance prediction modelingof The investigation 15th International and Experimental performance prediction modeling of asingle stage centrifugal pump operating as turbine a single stage cent," Energy Procedia, vol. 126,pp. 589-596, 2017.

[4] N. Dellinger and M. Dufresne, "Computational fluid dynamics modeling for the design ofArchimedes Screw Generator," vol. 118, 2018.

[5] H. B. Harja, H. Abdurrahim, S. Yoewono, and H. Riyanto, "Penentuan Dimensi Sudu dan SudutKemiringan Turbin Pada Turbin Ulir Archimedes," vol. 36, no. 1, 2014.

[6] C. Rorres, "The Turn of The Screw: Optimal Desibn of an Archimedes Screw," no. January, pp. 72-80, 2000.

[7] W. D. Lubitz, M. Lyons, and S. Simmons, "Performance Model of Archimedes Screw HydroTurbines with Variable Fill Level," Journal of Hydraulic Engineering, vol. 140, no. 10, p.04014050, 2014

[8] G. Dellinger, A. Terfous, and P. Garambois, "Experimental investigation and performance analysisof Archimedes screw generator," vol. 1686, no. March, 2016.

[9] K. Songin, "Experimental Analysis of Archimedes Screw Turbines," 2017.
[10] A. D. Nugroho and D. A. Himawanto, "Kajian Teoritik Pengaruh Geometri Dan Sudut Kemiringan Terhadap Kinerja Turbin Archimedes Screw," Seminar Nasional Teknologi Informasi dan Kedirgantaraan (SENATIK), vol. III, pp. 23373881, 2017.

[11] B. Yulistiyanto, H. Yul, and Lisdiyanti, "Pengaruh Debit Aliran dan Kemiringan Poros Turbin UlirPada Pembangkit Listrik Tenaga Mikro-hidro," Dinamika Teknik Sipil vol. 12, no. 1, pp. 1-5, 2012.

[12] T. Saroinsong, R. Soenoko, S. Wahyudi, and M. N. Sasongko, "Performance of threebladedArchimedes screw turbine," ARPN Journal of Engineering and Applied Sciences, vol. 11, no. 15, pp.9491-9495, 2016.

[13] S. R. Waters, "Analysing the performance of the Archimedes Screw Turbine within tidal rangetechnologies," no. November, pp. 1-171, 2015. 